\title{
Neurosarcoidosis: clinical manifestations, investigation and treatment
}

\author{
Desmond P Kidd
}

Centre for Neurosarcoidosis, Neuroimmunology unit, Institute of Immunology and Transplantation, University College London, London, UK

Correspondence to Dr Desmond P Kidd, Royal Free Hospital, London NW3 2QG, UK; d.kidd@ucl.ac.uk

Accepted 5 January 2020
D) Check for updates

(C) Author(s) (or their employer(s)) 2020. No commercial re-use. See rights and permissions. Published by BMJ.

To cite: Kidd DP. Pract Neurol 2020;20:199-212.

\begin{abstract}
Sarcoidosis affects the nervous system in $10 \%$ of cases. When it does so it can affect any part of the nervous system and with all degrees of severity. It forms part of the differential diagnosis in inflammatory, infective, neoplastic and degenerative neurological diseases and may be very difficult to diagnose without histological confirmation. Recent clinical studies and the increasing availability of new biological treatments allow a much clearer understanding of the disease. This review summarises its clinical features, imaging and laboratory characteristics, treatment and outcome.
\end{abstract}

\section{INTRODUCTION}

Sarcoidosis is an auto-inflammatory disorder characterised by the development of granulomatous inflammation in affected tissues. Any tissue may become affected, the most frequently being the lungs, skin, eyes and liver. The lymphatic system is always involved. At onset $95 \%$ of cases have demonstrable lung involvement, and half have multisystem disease ${ }^{1}$; over time this prevalence increases in those whose disease does not spontaneously remit. $^{2}$

\section{Clinical features}

The onset is subacute, rarely acute, with constitutional symptoms including feeling unwell, fever and night sweats before the heralding symptoms arise. Lofgren's syndrome is the coexistence of fever, arthritis of the ankles, erythema nodosum and hilar lymphadenopathy (figure 1). Heerfordt's syndrome comprises a granulomatous uveitis, parotid and submandibular salivary gland swelling and cranial neuropathy (usually but not always the facial nerve). Lung involvement is characterised by cough, breathlessness and chest tightness or stabbing pains, but is often asymptomatic. Any structure within the eye may be involved, and skin, cardiac, hepatic, renal, bone and joint involvement is common. ${ }^{3}$

Around $30 \%$ of cases resolve within 2 years, particularly with single system involvement, $30 \%$ have a relapsing form and $30 \%$ progressively deteriorate.

\section{Epidemiology}

Differences in the prevalence of the disease have been known for decades; it has long been known that the incidence is highest in Nordic countries $11-24$ per $10^{5},{ }^{4}$ and lowest in south-east Asian countries $(0.85$ in Korea, 2.17 in Taiwan and 1.01 in Japan). ${ }^{5-8}$ African Americans within the USA have three times the incidence of European Americans, ${ }^{9}$ and the incidence is lower still in Hispanic Americans. ${ }^{10}$ Recent studies from the Swedish registry of sarcoidosis have identified an annual incidence of 11 per $10^{5}$ and a prevalence of 160 per $10^{5},{ }^{11}$ and in the USA three studies have shown an annual incidence of 11 per $10^{5} .{ }^{12}$ In the UK the incidence was 14.5 per $10^{5}$ between 1977 and 1983 on the Isle of Man, ${ }^{13}$ and recently 9.7 per $10^{5}$ in a small study in Hertfordshire, in which the prevalence of multisystem disease at onset was seen to be $50 \% .{ }^{14}$

The age of onset varies, with very few cases occurring in children and the elderly, and a mean age of onset between 45 and 55 years, later in women than men. Overall it is more common in women than in men. ${ }^{15}$

Over time the mortality rate is greater than in the general population, around $7 \%,{ }^{16}$ relating predominately to the severity of the disease in those with respiratory, cardiac and neurological involvement, but also to an increased risk of infection. Patients with sarcoidosis also have more other morbidities, such as venous thromboembolism, cardiovascular disease and haematological and skin cancers, ${ }^{3}$ and 

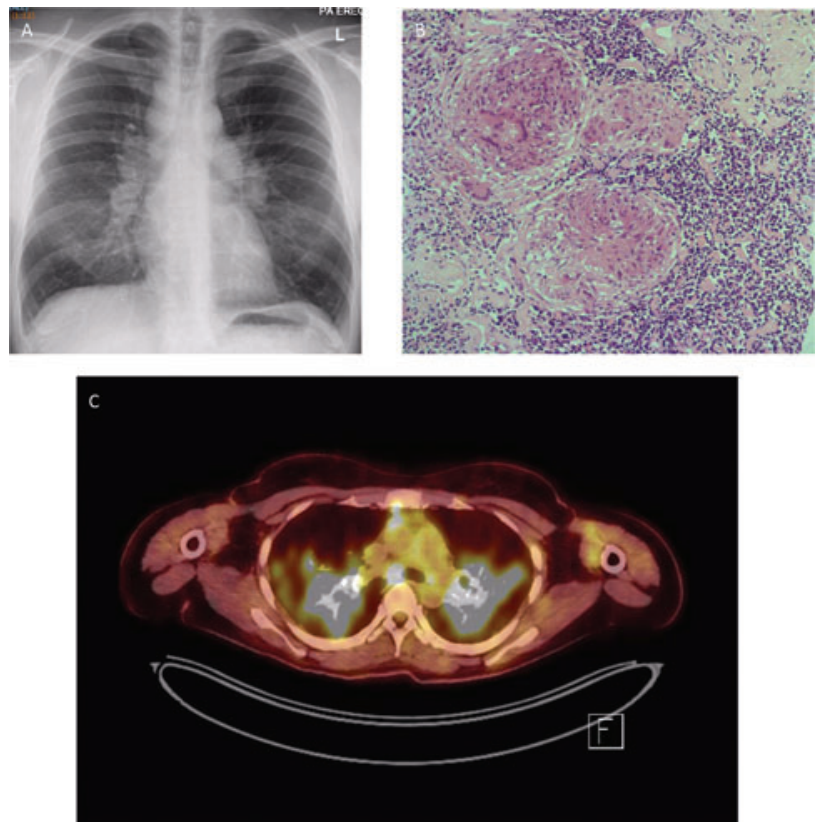

Figure 1 (A) Chest X-ray showing Garland's triad of bilateral symmetrical hilar lymphadenopathy and right para-tracheal lymphadenopathy. (B) H\&E-stained section of mediastinal lymph node $\times 400$ showing numerous well-formed granulomas and giant cells (courtesy Professor Peter Isaacson). (C) 18-FDG positron-emission tomogram axial image through the chest showing uptake within the mediastinal lymph nodes and the lung fields on both sides.

a higher prevalence of other autoimmune diseases, in particular thyroid disease, connective tissue diseases and multiple sclerosis. ${ }^{8} 1617$

\section{Neurological involvement}

Accounts of neurological complications in the disease began to be published as soon as it was recognised as a multisystem disease by Winckler in $1905,{ }^{18}$ and by Heerford 4 years later. ${ }^{19}$ A review in 1948 found 118 published cases, in which facial and optic neuropathies were seen most commonly, although any part of the nervous system was affected. ${ }^{20}$ Later cohort studies of 285-807 patients attending systemic sarcoidosis clinics identified an incidence of neurological involvement of $3.5 \%-7 \% .{ }^{19-23}$ More recent case series comprising $19-54$ cases $^{21-37}$ showed that around half of patients have isolated cranial neuropathies, of which the facial nerve is by far the most common, with peripheral nerve involvement in 10\% and muscle involvement in 5\%, and with brain and spinal cord lesions accounting for the remainder; $16 \%-70 \%$ of these series. The prevalence of neurological complications in one series from Japan was $7.2 \%{ }^{7}$

\section{Cranial neuropathy}

Facial neuropathy accounts for $70 \%$ of isolated cranial neuropathy. Most are unilateral and occur at the onset of the disease. Among those undergoing a spinal fluid examination, most have mild abnormalities of protein and cell count. Imaging is normal in half the cases, but in others shows nerve enhancement, and rarely shows more widespread changes in the absence of other clinical features. ${ }^{38}$

Optic neuropathy is common, ${ }^{20} 38-41$ arising through several different processes. A subacute optic neuritis is the most common and presents in an identical way to a demyelinating optic neuritis in most respects; pain is less prevalent, and the nadir acuity slightly less. Synchronous bilateral optic neuritis is uncommon, but sequential optic neuropathies occurred in $30 \%{ }^{41}$ Concurrent intraocular inflammation developed in $36 \%$ of one study. ${ }^{41}$ The associated field defects are central, centrocaecal or altitudinal.

An optic perineuritis occurs when the optic nerve sheath becomes inflamed, leading to visual field constriction, disc swelling and pain. Chiasmal involvement is common when a basal leptomeningitis involves the hypothalamus and adjacent structures. Finally, a compressive optic neuropathy may arise when a dural inflammatory mass, usually at the orbital apex, involves the optic nerve. There may also be sensory loss and pain.

Imaging usually shows the causative abnormality with enhancement of the inflamed area (figure 2). The cerebrospinal fluid (CSF) tends to be inactive or shows a mildly elevated CSF protein. Matched oligoclonal bands are uncommon; unmatched bands are not seen.

Isolated cranial neuropathies other than optic (II) and facial (VII) are less common but there are descriptions of each nerve being involved; the oculomotor (III), trochlear (IV and abducens (VI) were involved relatively frequently in previous series, the trigeminal (V) often alongside other nerves and the vestibulocochlear (VIII) proportionately less frequently. ${ }^{38}$ Imaging is usually normal, but there may be nerve enhancement. ${ }^{42}$ Inflammatory masses within the orbit, at the orbital apex and cavernous sinus may cause diplopia, trigeminal sensory loss and pain, and proptosis, ${ }^{40} 41$ and spread from an adjacent basal leptomeningitis may also involve these nerves.

Isolated hearing loss is uncommon in sarcoidosis; it occurs suddenly, often alongside a vestibular syndrome, progressively deteriorates ${ }^{43} 44$ and may fluctuate. ${ }^{23}$ Corticosteroids may rescue hearing ${ }^{43}$ but most do not recover. Imaging is either normal or shows a pachymeningeal thickening within the internal auditory canal. ${ }^{43} 44$ Spread from mastoid sinuses into the middle ear may also occur. The vestibulocochlear nerve may be involved as part of a spreading pachymeningitis or a leptomeningitis in the region, often with accompanying facial nerve palsy.

Isolated neuropathies of the lowest cranial nerves are uncommon, but I have often seen a bulbar disorder characterised by progressive dysphonia and dysphagia, although this is infrequent in the literature. ${ }^{20}$ Patients in my series were all female, and most had normal imaging but slightly active CSF. ${ }^{38}$ Occasionally there is weakness and atrophy of one side of the tongue. ${ }^{20}$ 

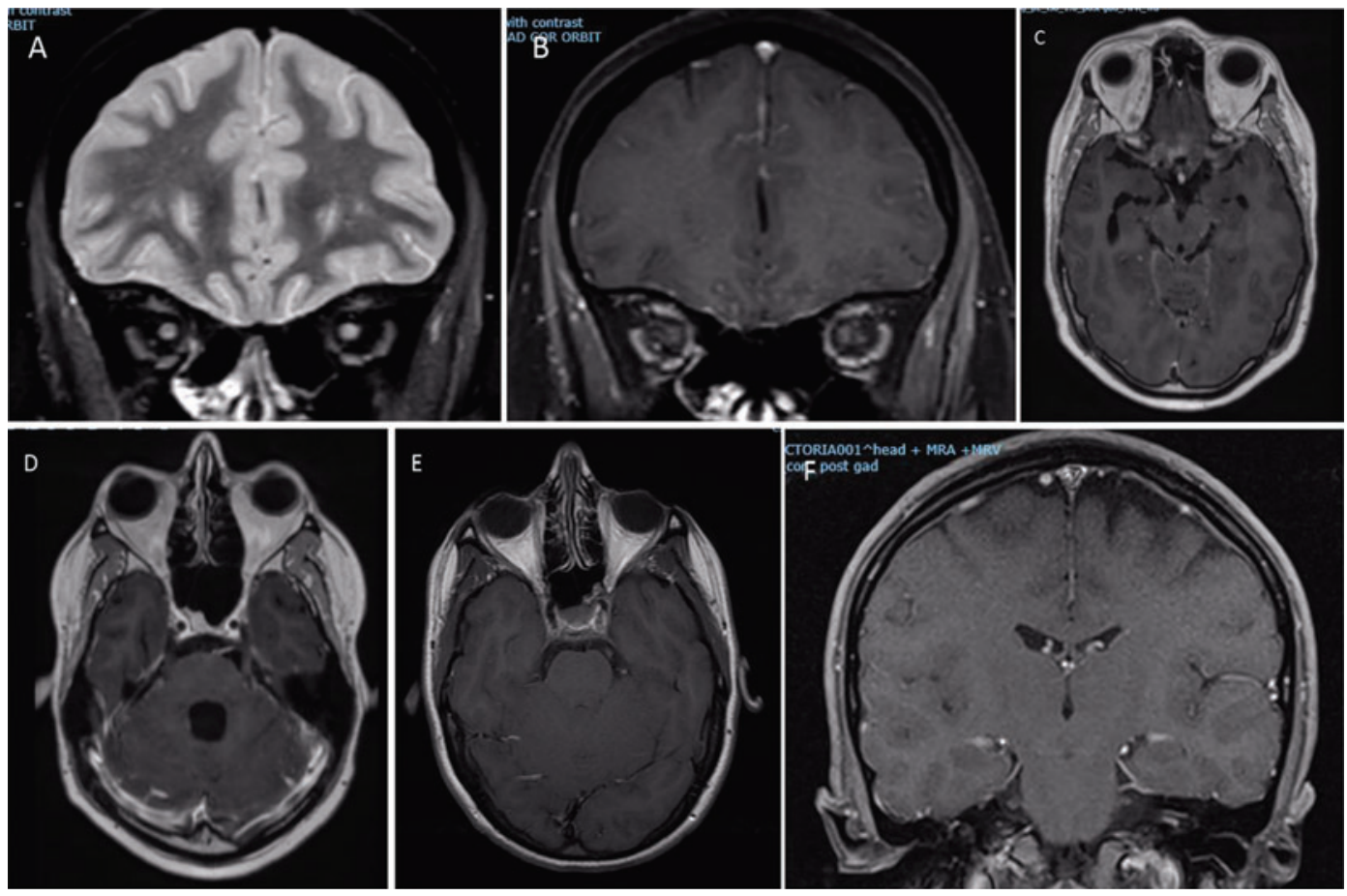

Figure 2 Cranial neuropathy in neurosarcoidosis. (A, B) Left optic neuropathy; high signal within the nerve with associated enhancement. (C) Enhancement of the right third nerve. (D) Enhancement of the left seventh nerve. (E, F) Enhancement of the left seventh and eighth nerves.

Again, involvement of these nerves may form part of a more widespread disorder due to a basal meningitis.

\section{Peripheral neuropathy}

Peripheral neuropathy accounts for $10 \%-14 \%$ of some series, but much less in others. Reports citing a high prevalence also note concomitant central neurological disorders and do not provide neurophysiological proof of peripheral involvement. My own view is that peripheral neuropathy is uncommon in sarcoidosis, accounting for $<5 \%$ of all cases, and is not associated with concomitant central neurological disease. It comprised only $0.3 \%$ of 3475 nerve biopsies carried out in a tertiary centre in Paris. ${ }^{45}$

The symptoms are sensorimotor or purely sensory, and the electrophysiological investigations point to an axonal pathology predominately, although there may be conduction slowing, focal conduction block and multifocal conduction block. ${ }^{46}{ }^{47}$ Mononeuritis multiplex and an asymmetric neuropathy may occur. ${ }^{45} 464849$ Mononeuropathies, particularly of the radial and ulnar nerves ${ }^{45} 4849$ can occur; in one case ${ }^{50}$ there was a granulomatous inflammatory mass in Guyon's canal.

An acute inflammatory demyelinating polyradiculoneuropathy is rare and seems to arise at the onset of the systemic disease; the electrophysiological findings are typical, but the CSF is active and includes a lymphocytosis. Corticosteroids appear to resolve the disorder. ${ }^{45} 485152$ The neuropathology is of a granulomatous infiltration of the epineurium with a perivascular infiltration of inflammatory cells and granulomas around the nerve (figure 3 ). There may be nerve fibre disorganisation and axonal loss. ${ }^{45} 465354$ Pathological features of a perineural vasculitis occurred in $40 \%$ of Professor Said's cases. Other authors have also noted that the neuropathy develops years after the onset of the systemic features.

There has not been a trial of treatment. There are reports of a response to intravenous immunoglobulin in those with a multifocal or demyelinating disorder, ${ }^{52}$ yet another was unresponsive to intravenous immunoglobulin who subsequently improved with corticosteroids. ${ }^{55} \mathrm{My}$ own treatment paradigm is to treat those with inflammatory neuropathies with intravenous immunoglobulin while also treating the systemic disease with immunosuppression, and managing those with an axonal pathology with treatment appropriate to the systemic disease alone; in my experience these patients tend not to deteriorate over time.

Small fibre neuropathy is also uncommon but associated with a severe and very poorly treatmentresponsive distal neuropathic pain. Large fibre nerve conduction studies are normal, thermal threshold and cutaneous autonomic responses subnormal, and intraepidermal nerve fibre density reduced in all cases. ${ }^{56}$ A series of 115 patients also had a high prevalence of accompanying autonomic symptoms (53\%) such as cardiovascular instability, disorders of sweating and gastrointestinal transit delay. ${ }^{57}$ Intravenous immunoglobulin, ${ }^{57}$ tumour necrosis factor alpha (TNF $\alpha)$ blockers ${ }^{58}$ and the 

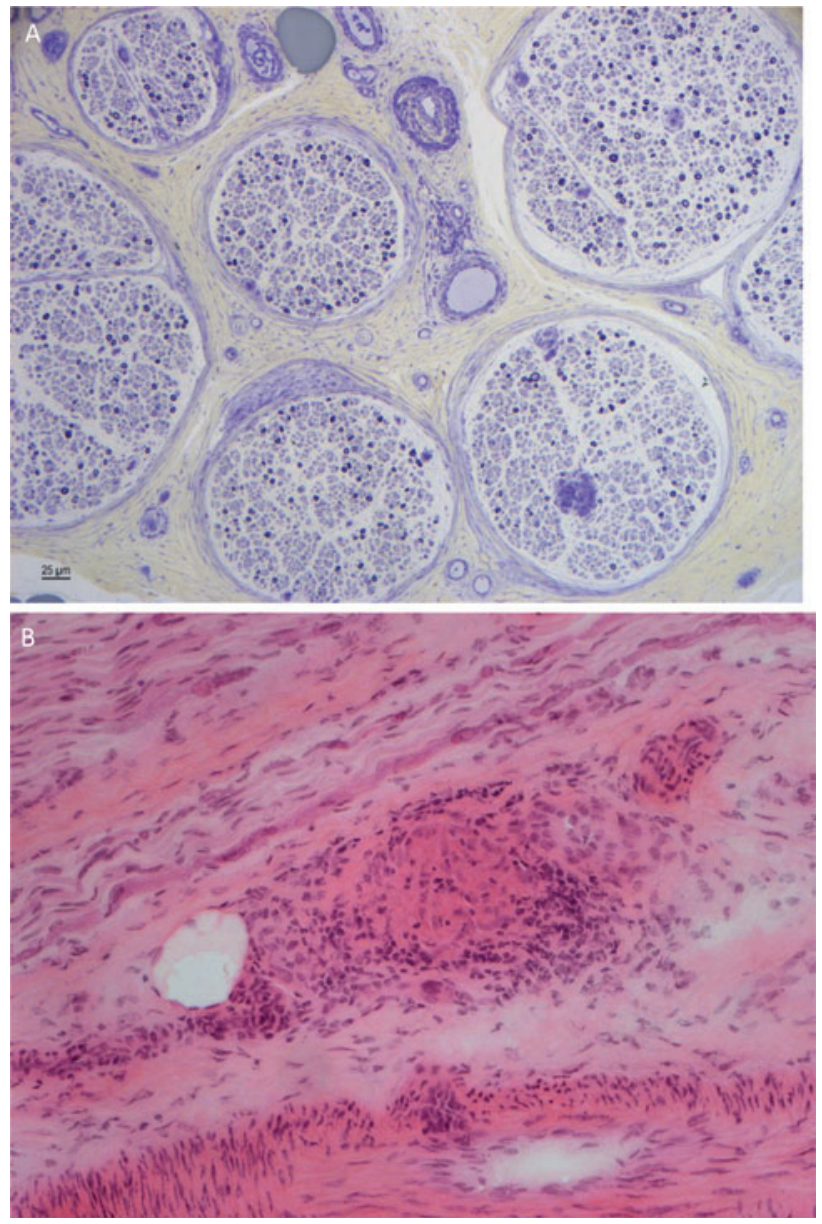

Figure 3 Sural nerve biopsy showing depletion of myelinated fibres, axonal degeneration and regenerative clusters (A). There is a perivascular cellular infiltrate with $T$ and $B$ lymphocytes and giant cells, and a granuloma (B) (courtesy Dr Rosalind King).

erythropoietin derivative ARA- $290^{59}$ can help the symptoms, but there has been no formal comparative trial of treatment; the disorder does not resolve. The pathogenesis is unknown, since there is no granulomatous inflammation within the nerves, but may relate to high circulating concentrations of chemokines, which induce hyperexcitability within fibres leading to the appreciation of pain; calcium influx induces an oxidative stress leading to axonal degeneration.

Some patients, at the onset of the systemic disease, present with a burning numbness of the chest wall that responds to corticosteroids and, in some cases, has been relapsing and corticosteroid-dependent for a time. Imaging of the spinal cord has been normal. Thoracic radiculopathy appears to be exclusive to sarcoidosis and is noted in early reports. Active CSF despite normal imaging suggests a meningitis of the dorsal spinal cord, picking off the roots as they leave to form intercostal nerves. Other cases ${ }^{60}{ }^{61}$ have prolonged $F$ wave responses, compatible with this assumption. The rapid resolution with corticosteroids and yet a propensity to relapse on withdrawal suggests that the nerve roots are inflamed; indeed, a recent report showed thoracic root enhancement in a patient with an adjacent paravertebral inflammatory mass. ${ }^{62}$

\section{Pituitary and hypothalamic involvement}

Hypothalamic involvement, in particular associated with diabetes insipidus, has featured in the literature from the earliest reports. Most present with endocrine symptoms, in particular polydipsia. ${ }^{63}{ }^{64}$ Most patients present with a gradual panhypopituitarism while others have endocrine involvement as part of an increasing leptomeningitis. Other presentations include headache, cranial neuropathies causing diplopia and facial sensory loss and of course visual symptoms caused by optic chiasm involvement. In my series of six cases, three had isolated pituitary involvement and in three the disease had spread to the adjacent cavernous sinus, causing third and sixth cranial neuropathies. Imaging was abnormal in all but one (figure 4). Those with hypothalamic involvement all had additional more widespread leptomeningeal disease and therefore other symptoms and signs. Two of these had enlargement of the stalk but not the gland; both had diabetes insipidus.

Endocrine investigations mostly identify gonadotropin and thyrotropin deficiency, diabetes insipidus in over half and corticoadrenal insufficiency in the least. ${ }^{6364}$ Most do not improve with treatment despite a radiological response, although some recover completely. ${ }^{63}$

\section{Brain involvement}

Granulomatous inflammation may involve the central nervous system through three processes: a pachymeningitis, a leptomeningitis and a vasculitis (figure 5).

\section{Pachymeningitis}

Dural inflammation may develop in any part of the cranial cavity; the basal regions and the convexity. Around half present as mass lesions with focal neurological signs, often with seizures. The remainder have a multifocal en plaque type appearance that may be very widespread. ${ }^{38}$ Headache is common, and no one in this patient group in my series had hydrocephalus. When the cavernous sinus and orbital apex were involved, patients presented with pain, diplopia and optic neuropathy. The CSF was active in most but this did not correlate with clinical features or severity. ${ }^{38}$ Imaging was abnormal in every case (figure 6).

Patients thus present with headache and focal neurological signs and are less impaired than those with a leptomeningitis. Following treatment, which is required for several years, the outcome is good. ${ }^{65}$

\section{Leptomeningitis}

$75 \%$ of cases in the Royal Free series ${ }^{38}$ showed features of an invasive and destructive meningoencephalitis. 


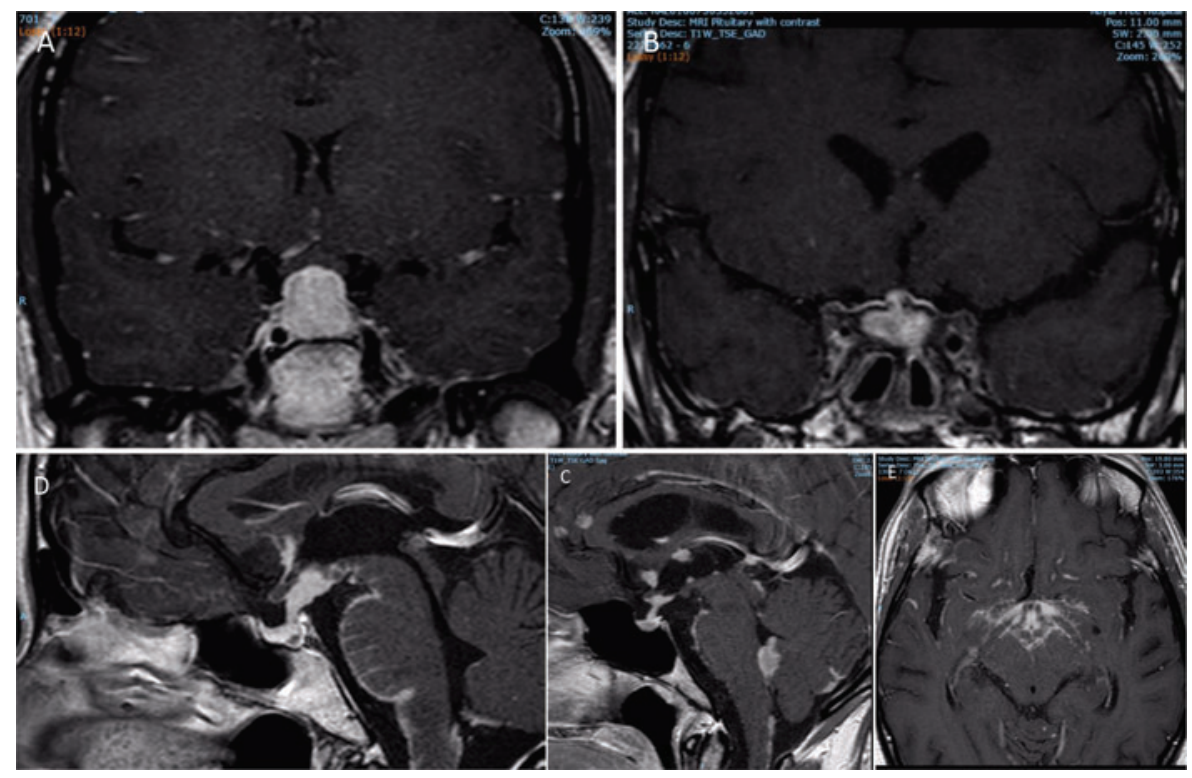

Figure 4 Involvement of the pituitary and hypothalamus. (A) Isolated enlargement of the anterior pituitary presenting with headache and visual loss. (B) Anterior pituitary mass with adjacent leptomeningeal involvement extending into the cavernous sinuses on both sides. The patient presented with diplopia and was found to have asymptomatic hypopituitarism. (C) Widespread nodular leptomeningeal disease with enlargement of the anterior and posterior pituitary extending into the hypothalamus. (D) More widespread leptomeningeal disease most prominent within the hypothalamus. (E) Leptomeningeal disease of the brainstem, optic chiasm and hypothalamus.

Two-thirds presented with signs of diencephalic dysfunction and hydrocephalus, while a third had signs of involvement of the brainstem, with associated hydrocephalus. The basal meninges were more commonly involved than the convexities. The disease course was subacute but increasingly rapid, with rapid accrual of a severe encephalopathy and neurological signs. These patients are more disabled than those with a pachymeningitis, ${ }^{65}$ and the two processes do not seem to overlap.

Imaging was abnormal in every case (figure 7). The CSF was active in most cases, with a high protein concentration and cell count and low CSF/serum glucose ratios. CSF protein concentration correlated with the presence of hydrocephalus.
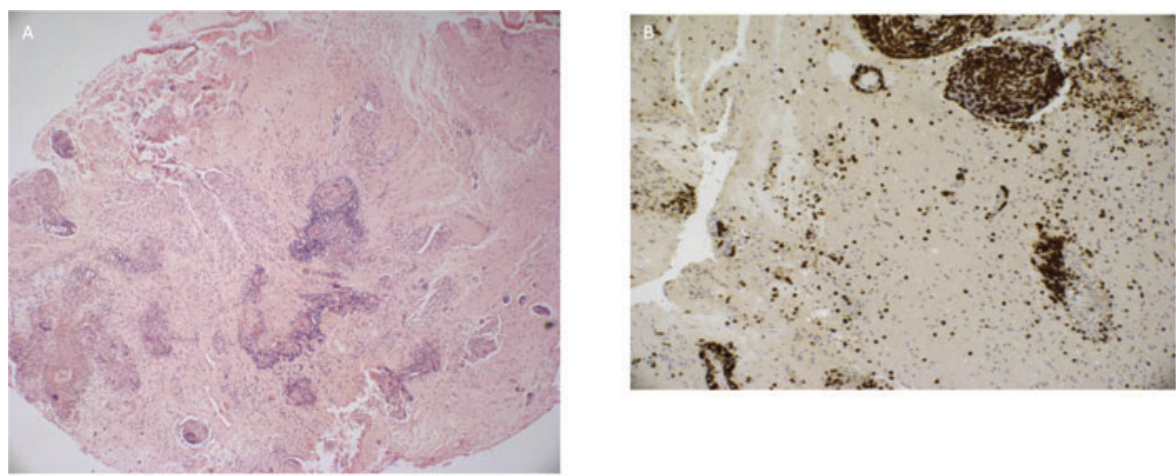

Figure 5 Neuropathology of neurosarcoidosis: H\&E-stained sections (A, C, D) of brain (A, C) and leptomeninges (D) showing a prominent infiltration of small well-formed epithelioid granulomas surrounded by lymphocytes (B) and plasma cells (courtesy Dr Malcolm Galloway). 

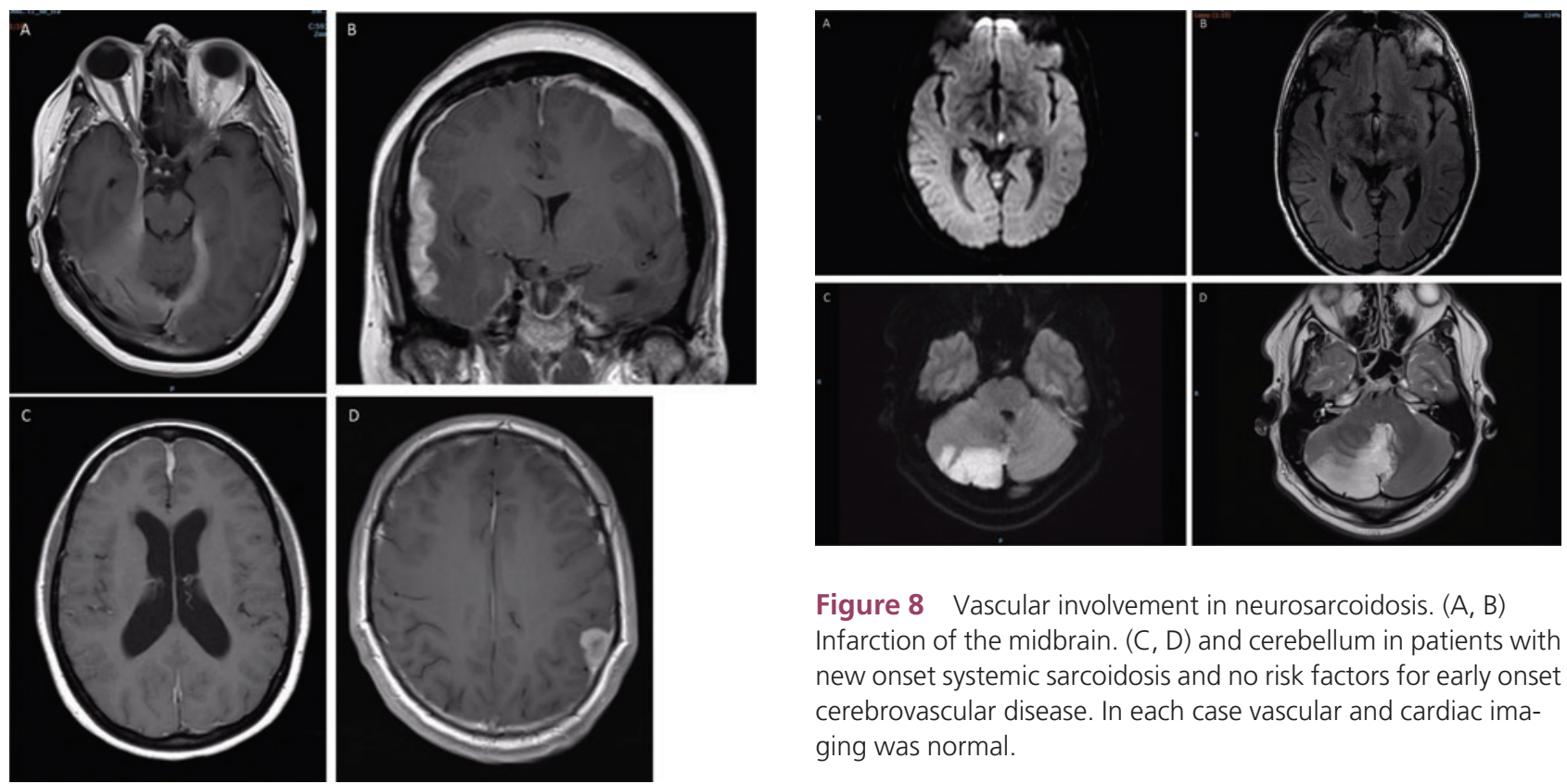

Figure 8 Vascular involvement in neurosarcoidosis. (A, B) Infarction of the midbrain. (C, D) and cerebellum in patients with new onset systemic sarcoidosis and no risk factors for early onset cerebrovascular disease. In each case vascular and cardiac imaging was normal.

Figure 6 Pachymeningeal disease in neurosarcoidosis. Each patient presented with headache and focal neurological signs. Patient $D$ had had a seizure.

Treatment should be intensive; corticosteroids alone will not be sufficient and may lead to repeated relapse leading to irreversible neurological impairment. The outcome depends on the timing and type of treatment (figure 8).

\section{Vascular involvement}

Early pathological descriptions showed that the predominate pathological process was a granulomatous inflammation within the leptomeninges, spreading into the subjacent parenchyma. ${ }^{66-68}$ Occasionally the walls of small and medium-sized arteries show epithelioid cell

invasion, leading to an inflammatory response with disrupted internal elastic lamina and fibrosis, together leading to occlusion or stenosis of the vessel lumen. ${ }^{66}$ However, only one report noted infarction of the adjacent parenchyma. ${ }^{68}$

Clearly, therefore, vascular involvement does occur but the small number of case reports available implies that it rarely has a direct clinical consequence; such reports include infarction due to large vessel occlusion occurring without prelude, ${ }^{69-72}$ while others note a crescendo series of transient ischaemic attacks culminating in infarction. ${ }^{72-74}$ Half these cases had an adjacent leptomeningeal enhancement while the others showed only vascular changes on imaging (figure 9). ${ }^{69-71} 74$ Antiplatelet therapy does not reduce the frequency of attacks, ${ }^{73}$ whereas corticosteroids do. ${ }^{72} 74$
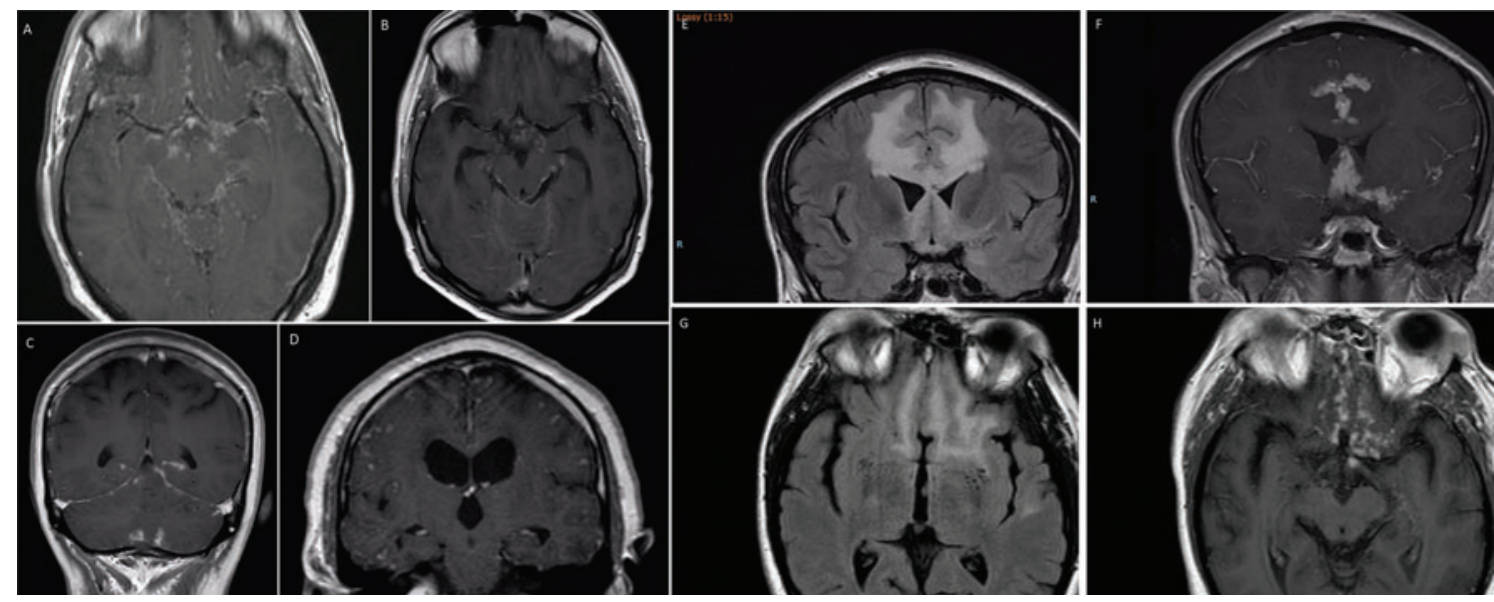

Figure 7 Leptomeningeal disease in neurosarcoidosis. (A) Widespread basal leptomeningeal enhancement involving the diencephalon and brainstem. $(B, C)$ More localised nodular leptomeningeal enhancement of the brainstem and the cerebellum. (D) Widespread enhancement extending into the brain causing a subacute encephalopathy with headache. $(E, F, G, H) A$ severe destructive invasive leptomeningitis of the frontal and temporal regions leading in both cases to impairments of cognitive function, motor control and seizures. 


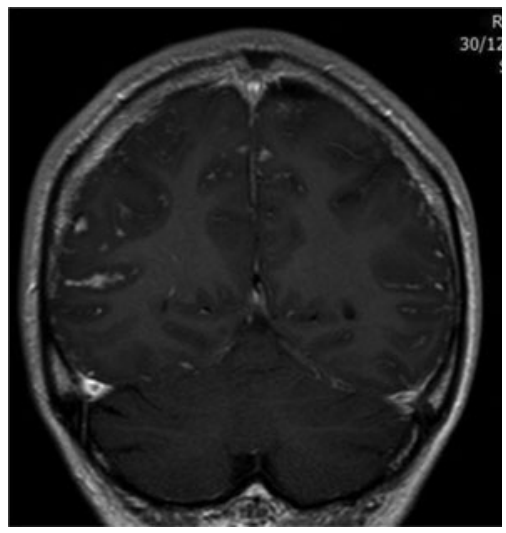

Figure 9 Enhancement of parenchymal vessels in neurosarcoidosis.

Arteriography may be normal, ${ }^{69} 7074$ or show focal stenosis of the anterior cerebral artery, middle cerebral artery and internal carotid artery; abnormalities resembling moyamoya may develop. ${ }^{71-737576}$ A recent case showed that this probably relates to a large vessel arteritis. ${ }^{77}$ Another series has confirmed that vessel wall enhancement related to stroke in more than half the cases compared with $18 \%$ of those with inflammation and no radiological signs of infarction (figure 9). ${ }^{78}$
Intracranial haemorrhage is also rare ${ }^{79}$ probably as uncommon as cerebral infarction. Patients all have clear concurrent evidence for a granulomatous leptomeningitis. The haemorrhage may be subarachnoid but more commonly is lobar. They may be multiple, ${ }^{80}$ infratentorial $^{79}$ and in one case within the spinal cord. $^{81}$ A neuropathological examination showed inflammation within and disruption of the integrity of the walls of small veins, suggesting an inflammation of the wall leading to leakage at low pressure. ${ }^{79}$ Recent reports of vein wall enhancement and venous engorgement in the medullary veins on vessel wall imaging ${ }^{82}$ and susceptibility-weighted MRI ${ }^{83}$ support this hypothesis.

\section{Spinal cord and cauda equina involvement}

Involvement of the whole cranium and spinal canal is common both in leptomeningeal and pachymeningeal forms of the condition, but isolated disease of the spinal cord and cauda equina does occur. Most present with a subacute spinal cord lesion, in which there is a single cervical or thoracic longitudinally extensive lesion, associated with adjacent leptomeningeal enhancement (figure 10A-D). $.^{38} 84-88$ Pachymeningeal lesions tend to be smaller and present as compressive lesions. Half of those with lower dorsal lesions also have cauda equina
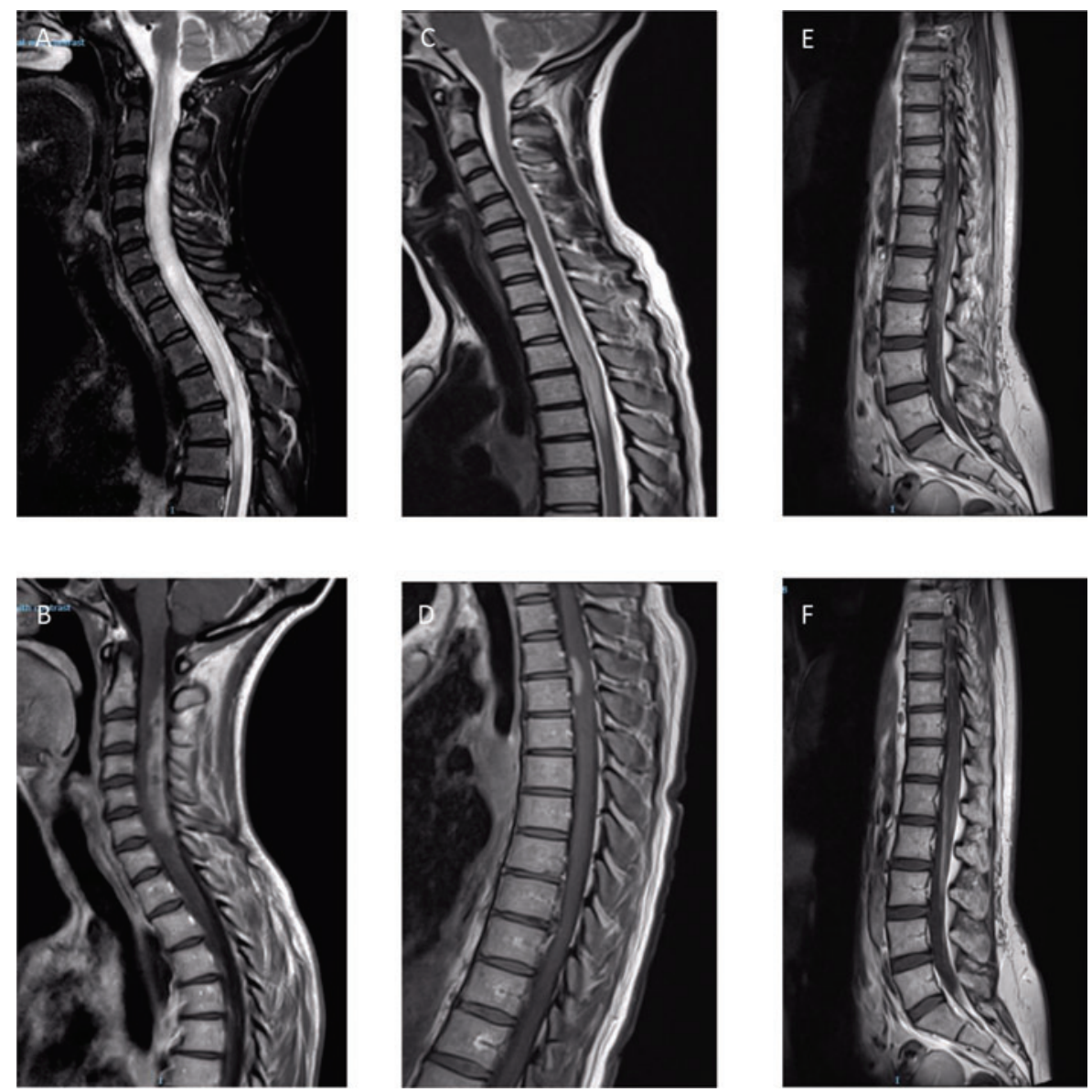

Figure 10 T2-weighted and T1-weighted MRI following contrast administration showing $(A, B)$ a lesion of the cervical and (C, D) thoracic cord and $(E, F)$ cauda equina showing enhancement of inflamed nerve roots. 
involvement, with nodules of enhancement on the descending roots (figure 10E,F). ${ }^{38}{ }^{89}$ Individual roots may also be affected. The signs of a cauda equina lesion involve early sphincter disturbance and a predominately sensory disorder; it is rarely painful. However, a motor disorder comprising a single motor root usually is painful.

A progressive cord lesion is less common; in this situation imaging tends to be normal or showing signs of atrophy ${ }^{38}$; when there is an accompanying amyotrophy due to root involvement, this may be difficult to distinguish from motor neuron disease, but the CSF tends to show active cells.

\section{Isolated neurosarcoidosis}

Patients may present with a neurological disorder characterised by granulomatous inflammation with no clear signs on imaging of a systemic disease. Often patients present with the neurological disorder and signs of the systemic disease are identified by search; in some no evidence is found, in others the systemic features develop only later. ${ }^{90}$ The imaging features and CSF abnormalities are similar to those with systemic disease as well, ${ }^{38}$ except that only those with isolated neurosarcoidosis have unmatched oligoclonal bands. A series of 10 patients from two US centres found no difference in clinical, imaging or CSF features of the disease. ${ }^{91}$ A comprehensive search for a masked infection or tumour is essential in these patients.

\section{Imaging}

MRI is the most important imaging modality; in one recent series ${ }^{38}$ it was abnormal in 35\% of those with cranial neuropathy other than optic neuropathy, and $100 \%$ of those with central neurological disease. It is essential to give a paramagnetic contrast agent, since contrast enhancement is often the only abnormality, and only a small minority show no enhancement. As noted above, meningeal enhancement correlates with the site of the disease, and in leptomeningeal disease enhancement and oedema of the subjacent cortex and white matter is common, and some patients show enhancement of the affected vessel walls. ${ }^{77} 78$ Patients with progressive spinal cord disease may have no abnormalities or atrophy, and those with vascular involvement as noted above, may only have abnormalities of perfusion, diffusion or magnetic susceptibility. Positron emission tomography (PET) studies with 18 -FDG ${ }^{92} 93$ may show abnormalities when postcontrast MRI does not.

\section{Cerebrospinal fluid}

The CSF is always active in untreated neurosarcoidosis. The protein is raised, there is a lymphocytosis, and the CSF/plasma glucose ratio is reduced. In a recent series of 128 patients with neurosarcoidosis affecting the brain, spinal cord and cauda equina, ${ }^{38}$ the median CSF protein was $0.8(0.19-8.35) \mathrm{g} / \mathrm{L}$, and raised in $76 \%$ of 89 samples. The median CSF white cell count was $5(0-395)$ cells $/ \mu \mathrm{L}$, and raised in $51 \%$ of samples. The CSF to plasma glucose ratio was reduced in $81 \%$, median $48 \% .^{20-79} 9495$ Patients with isolated cranial neuropathies had less active CSF than those with more widespread disease, in whom CSF protein correlated both with the presence of hydrocephalus, and with disability as measured by the modified Rankin score. Those with cauda equina involvement had a higher CSF protein than those with isolated spinal cord involvement. CSF cell count and glucose ratio did not correlate with disability.

Oligoclonal bands were negative in serum and CSF in $73 \%$ of this series, and there were matched bands in $23 \%$. The presence of matched bands correlated with CSF protein, implying a relationship with disease severity. Unmatched oligoclonal bands occurred only in the small group with isolated neurological involvement. In another series ${ }^{96}$ patients with MRI-visible leptomeningitis had higher CSF cell counts and protein concentrations, and a lower glucose concentration, than those without enhancement.

In those with peripheral neuropathy the CSF protein is modestly raised, with matched oligoclonal bands but without cells. In my series of small fibre neuropathy the CSF was inactive but there are no data from other studies.

\section{Serum biomarkers}

At the onset of the systemic disease a peripheral lymphopenia is common (due to accumulation of activated $\mathrm{T}$ cells at the sites of inflammation). There is also a cytokine and chemokine pattern in the serum, although this varies with the clinical syndrome and the disease time course. ${ }^{97} \mathrm{IgG}$ deficiency may also develop.

Raised serum calcium (due to upregulation by granulomas of an enzyme that converts 25 -hydroxy vitamin $\mathrm{D}$ to 1,25 dihydroxy vitamin D) occurs in $10 \%$ of cases, and hypercalciuria in a further $40 \%$.

Angiotensin-converting enzyme (ACE) is secreted by alveolar granulomas and $60 \%$ of patients with systemic sarcoidosis have a raised serum ACE concentration. It is not useful as a disease monitor since it does not always rise again in relapse and does not define disease progression in lung disease. ${ }^{98}$ It is also raised in numerous infections, including tuberculosis, other inflammatory illnesses and in diabetes mellitus, hypothyroidism and lymphoma.

Serum amyloid A1 is also released by activated macrophages and may be raised when the serum C-reactive protein is not. It regulates granuloma formation through toll-like receptor 2. Lysozyme, neopterin and chitotriosidase are also released by macrophages and are raised in blood and in bronchoalveolar lavage fluid, ${ }^{98}$ but none is specific for sarcoidosis. 
A recent comparative study of ACE, chitotriosidase, lysozyme and KL- 6 found that KL-6 is associated with lung fibrosis and that a raised chitotriosidase had a specificity of $85 \%$ in sarcoidosis. ${ }^{99}$

\section{CSF biomarkers}

The spinal fluid assay results from a large series are summarised above. The CD4/CD8 ratio is raised in CSF (and broncho-alveolar lavage fluid) in people with neurosarcoidosis; in one study, ${ }^{100}$ the interleukin 6 (IL6) and IL-10 concentrations were raised, more than in multiple sclerosis, and more in patients with active disease than in those previously treated. CSF cytokines are raised in all inflammatory and infective neurological diseases, and we need further work to define the relevance of these features in the diagnosis of neurosarcoidosis. CSF ACE is not a biomarker; ACE increases in proportion to CSF protein and is raised in any inflammatory or infective disease in which the protein is raised.

\section{Differential diagnosis}

The need for a histologically sound basis for the diagnosis is increasing as specific biological therapies are developed. The differential diagnosis is complex and wide ranging; neoplastic disorders such as lymphoma, meningioma, glioma, choristomas and metastatic carcinomas may all cause a clinical syndrome with radiological abnormalities consistent with the disease, and indeed granulomatous inflammation may develop adjacent to a neoplastic lesion, particularly lymphoma and germinoma. Infectious diseases due to Mycobacterium tuberculosis, M. leprae, spirochaetae, brucella, bartonella, toxoplasma and various parasites and fungi may also do so. Other granulomatous diseases that affect the nervous system include primary angiitis of the central nervous system and idiopathic hypertrophic pachymeningitis. Lymphocytic disorders may give similar imaging and clinical appearances, including chronic lymphocytic inflammation with pontine perivascular enhancement responsive to steroids (CLIPPERS), the recently described auto-immune glial fibrillar acidic protein astrocytopathy, the neurological complications of systemic lupus erythematosus, Sjögren's syndrome and rheumatoid arthritis, neuromyelitis optica spectrum disorder, IgG4-related disease and cryopyrinassociated periodic syndrome. Histiocytic diseases such as Langerhans cell histiocytosis, ErdheimChester disease and Rosai-Dorfman syndrome may also cause disorders with identical imaging to neurosarcoidosis. Systemic and neurological granulomatous disease may also arise in inherited immunodeficiency disorders and as part of an immune reconstitution syndrome in acquired immunodeficiency. Sarcoid-like reactions may also arise during immune treatment of neoplastic and inflammatory diseases such as rheumatoid arthritis (with TNF $\alpha$ and IL-6 blockers), multiple sclerosis (with interferon $\beta$, daclizumab and alemtuzumab) and during cancer treatment with immune checkpoint inhibitors.

Patients with systemic sarcoidosis have an increased prevalence of certain neurological infections, in particular cryptococcus, listeria and progressive multifocal leukoencephalopathy; a brain lesion in sarcoidosis does not automatically reflect spread of the inflammatory condition into the nervous system. Finally, as noted above, patients with sarcoidosis are at increased risk of developing other inflammatory diseases, including multiple sclerosis, undoubtedly owing to their genetic susceptibility to develop other immunological diseases.

\section{Diagnosis and diagnostic criteria}

I am surprised still to learn of patients diagnosed with neurosarcoidosis on the basis of having ruled out multiple sclerosis and neuromyelitis optica spectrum diseases, the criterion seemingly being, 'What else might it be?'. This is particularly likely when the neurological disorder is associated with inflammatory ocular disease, which may complicate many other inflammatory, infective and neoplastic diseases, and which not even be associated with the neurological disease of sarcoidosis. There is a large list of conditions that can simulate the clinical and imaging characteristics of neurosarcoidosis, and it is very important to understand that a neoplastic and infective diseases can initiate a granulomatous disease. ${ }^{101}$ All of this makes it virtually impossible to create meaningful and specific diagnostic criteria. The concept of definite, probable and possible neurosarcoidosis is understandable, but it can readily be seen that patients with biopsy-proven granulomatous disease of the central nervous system (CNS) may not have sarcoidosis, and that it is impossible to diagnose possible neurosarcoidosis with any certainty whatsoever, given that there is no evidence for sarcoidosis systemically and no confirmation that the neurological disorder is granulomatous,. More recently the World Association of Sarcoidosis and Other Granulomas Diseases ${ }^{102}$ has published a carefully considered organ assessment instrument that will be much more useful to clinical trials and research than the previously published diagnostic criteria. In addition, a consortium of American experts has compiled a clearly considered summary of the investigation of the disease and notes 'one can never be 100\% certain of the diagnosis of sarcoidosis, even with a brain biopsy ..., ${ }^{103}$ and provides a further proposal for diagnostic criteria, disappointingly although understandably continuing with the theme of definite, probable and possible forms of the disease.

Over time genetic and biochemical markers will replace any clinical criterion, and we can only hope that this occurs soon.

\section{Treatment and outcome}

Neurosarcoidosis is a treatable disease and its management in a correct and timely way can avoid patients 


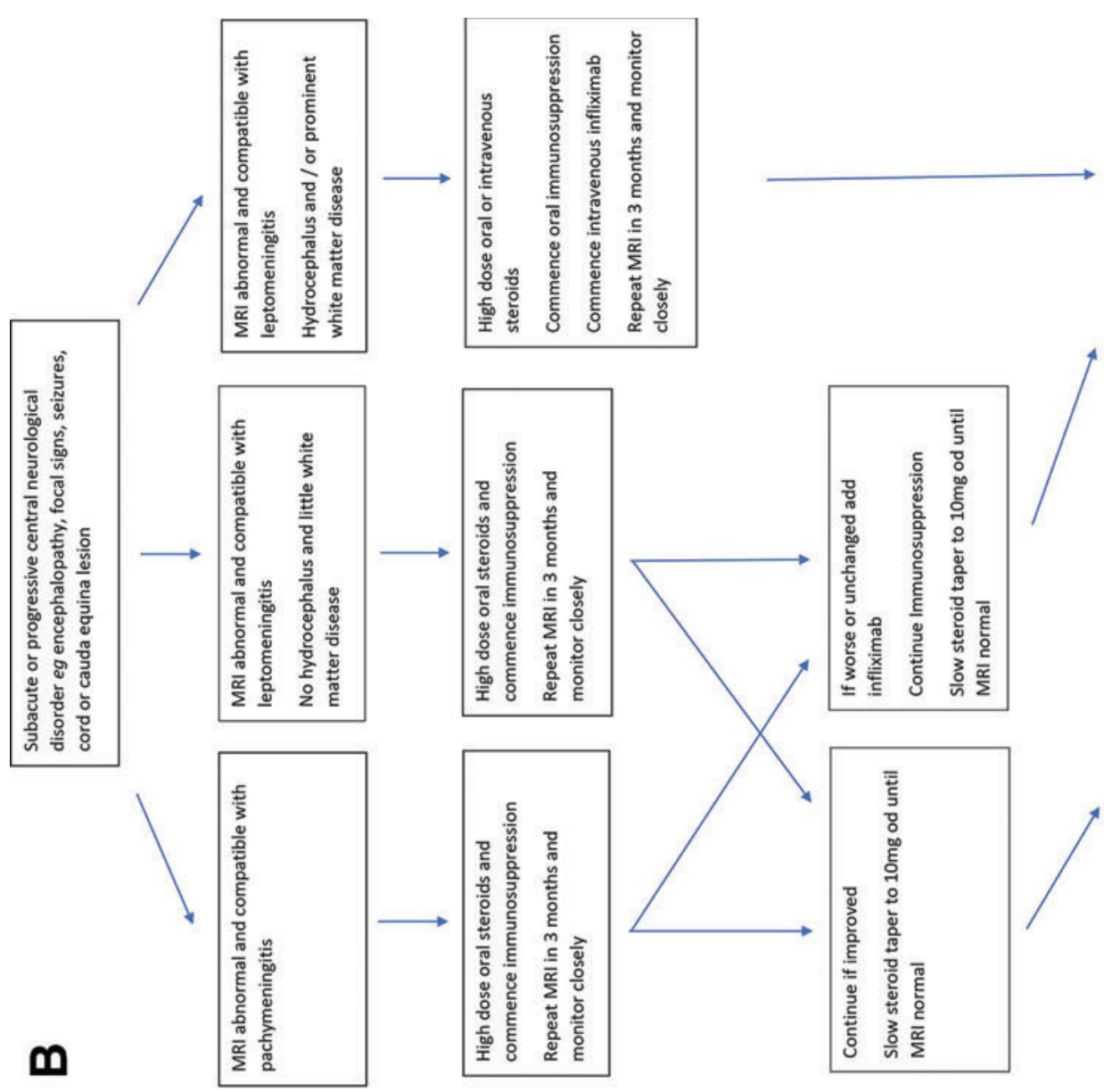

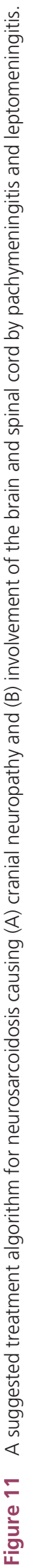


having severe residual neurological impairments. ${ }^{65}$ Corticosteroids form the basis of treatment in all granulomatous diseases; the inflammation is corticosteroidresponsive but relapses readily if treatment is reduced too quickly. Some require very high doses (even $100 \mathrm{mg} /$ day) to maintain a treatment response; over time the disease ameliorates, and the dose may reduce without relapse. Immunosuppressive agents are essential not only as steroid-sparing but as disease modifiers; corticosteroids reduce the inflammation, but the immunosuppressive agent prevents it from returning. Methotrexate, mycophenolate mofetil and azathioprine are all used; methotrexate is better than mycophenolate mofetil in systemic ${ }^{104}$ and neurological disease, ${ }^{105}$ and I have not found azathioprine sufficiently effective in central neurological disease. The standard dose of methotrexate is $15-20 \mathrm{mg}$ weekly with folate rescue, with the dose altered according to the effect on the disease, the corticosteroid dose, and the prevalence of adverse effects. Intravenous cyclophosphamide may be used for severe disease; it has more adverse effects including serious infections but is associated with reduced relapse frequency. ${ }^{106}$

The biological agent infliximab, which blocks TNF $\alpha$ receptors through binding to TNF $\alpha$, is effective in the systemic and ocular forms of the disease $e^{107} 108$ and in those with neurological involvement. ${ }^{65} 109110$ Its use has substantially improved the outcome of treatment in severe forms of the disease, particularly invasive leptomeningeal disease and treatment-resistant pachymeningeal disease, ${ }^{65}$ and may over time remove the disease entirely. ${ }^{65}$ However, this takes $2-5$ years of continual treatment. Incomplete treatment risks early relapse following treatment withdrawal ${ }^{108} 109$ 111-113; in one series this was $50 \%$ in patients for whom treatment was stopped after a year, but when treatment continues until meningeal enhancement resolves (over $18-36$ months) the risk of relapse was less than $10 \%{ }^{65}$ Use of biosimilars is currently being studied; in one series ${ }^{111}$ patients starting with a biosimilar seemed to respond as well as those treated with originator (although both groups relapsed). However, it may be hazardous to switch from originator to biosimilar during treatment, ${ }^{111}$ including recurrence of leptomeningeal enhancement and the development of hydrocephalus. ${ }^{114}$ It may be safe to use biosimilars from treatment onset; further study is required to define this and to ascertain whether or not the response is the same. Other TNF $\alpha$ blockers have less effect; adalimumab is slower to take effect, and golimumab and etanercept have not shown an effect in respiratory involvement, ${ }^{115}$ and etanercept can cause sarcoidosis in patients who receive this to treat connective tissue diseases.

There are isolated reports of a response to the IL-6 blocker tocilizumab, ${ }^{100} 116$ and the CD-20 antagonist rituximab $^{117}$ but the IL-17 blocker ustekinumab does not help the respiratory disease. ${ }^{118}$ Since janus kinase/ signal transducers and activators of transcription (JAKSTAT) signalling may occur in the pathogenesis of sarcoidosis, Janus kinase inhibitors may be beneficial ${ }^{119}$; there are recent reports of an effect in cutaneous and respiratory disease. ${ }^{120}$ Inhibitors of mammalian target of rapamycin complex 1 (mTORC1) may also play a role in the future. ${ }^{121}$

Perhaps 20\% of patients with neurosarcoidosis need biological therapies ${ }^{65}$; those with cranial neuropathy and peripheral neuropathy respond to an increase in treatment for the systemic disease, and this is usually sufficient; there is only a small risk of relapse or of further symptom, and there is no evidence that patients with peripheral nerve involvement have a coexisting central neurological disease. Most patients with a mild central disease of the brain or spinal cord respond to oral corticosteroids and immunosuppression. Those with rapid onset disease in whom it is clear that the disease is destructive and deteriorating should be treated urgently with biological therapies. Figure 11 shows a treatment paradigm developed in our unit and based on experience of treatment of 235 cases.

\section{Key points}

Neurosarcoidosis is uncommon, occurring in $5 \%$ of those with the systemic disease and 2 per 100000 of the general population.

- Seventy per cent have a mild disease comprising cranial neuropathy, radiculopathy and peripheral small-fibre or large-fibre neuropathy.

- Thirty per cent have a severe CNS inflammatory disease requiring corticosteroids and immunosuppression; those with severe disease at onset or those who are treatment unresponsive should receive biological therapies, including TNF $\alpha$ antagonists.

\section{FURTHER READING}

1. Grunewald J, Grutters JC, Arkema EV, et al. Sarcoidosis. Nat Rev Dis Primers 2019;5:45.

2. Kidd DP. Sarcoidosis of the central nervous system: clinical features, imaging and CSF results. J Neurol 2018;265:1906-15.

Contributors DPK wrote this review and was responsible for the interpretation of the data presented and the cited literature.

Funding The author has not declared a specific grant for this research from any funding agency in the public, commercial or not-for-profit sectors.

Competing interests None declared.

Patient consent for publication Not required.

Provenance and peer review Commissioned; externally peer reviewed.

ORCID iD

Desmond P Kidd http://orcid.org/0000-0002-2415-9011 


\section{REFERENCES}

1 Baughman RP, Teirstein AS, Judson MA, et al. Clinical characteristics of patients in a case control study of sarcoidosis. Am J Respir Crit Care Med 1889;2001:1885.

2 Judson MA, Baughman RP, Thompson BW, et al. Two year prognosis of sarcoidosis: the access experience. Sarcoidosis Vasc Diffuse Lung Dis 2003;20:204-11.

3 Grunewald J, Grutters JC, Arkema EV, et al. Sarcoidosis. Nat Rev Dis Primers 2019;5:45.

4 Arkema EV, Cozier YC. Epidemiology of sarcoidosis: current findings and future directions. Ther Adv Chronic Dis 2018;9:227-40.

5 Yoon H-Y, Kim HM, Kim Y-J, et al. Prevalence and incidence of sarcoidosis in Korea: a nationwide population-based study. Respir Res 2018;19:158.

6 Pietinalho A, Hiraga Y, Hosoda Y, et al. The frequency of sarcoidosis in Finland and Hokkaido, Japan. A comparative epidemiological study. Sarcoidosis 1995;12:61-7.

7 Morimoto T, Azuma A, Abe S, et al. Epidemiology of sarcoidosis in Japan. Eur Respir J 2008;31:372-9.

$8 \mathrm{CH} \mathrm{W}$, Chung PI, CY W, et al. Comorbid autoimmune disease in patients with sarcoidosis: a nationwide case-control study in Taiwan. J Dermatol 2017;44:423-30.

9 Rybicki BA, Major M, Popovich J, et al. Racial differences in sarcoidosis incidence: a 5-year study in a health maintenance organization. Am J Epidemiol 1997;145:234-41.

10 Baughman RP, Field S, Costabel U, et al. Sarcoidosis in America. analysis based on health care use. Ann Am Thorac Soc 2016;13:1244-52.

11 Arkema EV, Grunewald J, Kullberg S, et al. Sarcoidosis incidence and prevalence: a nationwide register-based assessment in Sweden. Eur Respir J 2016;48:1690-9.

12 Ungprasert P, Carmona EM, Utz JP, et al. Epidemiology of sarcoidosis 1946 -2013: a population-based study. Mayo Clin Proc 2016:183-8.

13 Parkes SA, Baker SB, Bourdillon RE, et al. Incidence of sarcoidosis in the Isle of man. Thorax 1985;40:284-7.

14 Kidd DP. The epidemiology of systemic sarcoidosis in eastern Hertfordshire, UK. Annals of Public Health Reports 2018;2:22-5.

15 Ungprasert P, Crowson CS, Matteson EL. Influence of gender on epidemiology and clinical manifestations of sarcoidosis: a population-based retrospective cohort study 1976-2013. Lung 2017;195:87-91.

16 Rajoriya N, Wotton CJ, Yeates DGR, et al. Immune-Mediated and chronic inflammatory disease in people with sarcoidosis: disease associations in a large UK database. PMJ 2003;85:233-7.

17 Terwiel M, Grutters JC, van Moorsel CHM. Clustering of immune-mediated diseases in sarcoidosis. Curr Opin Pulm Med 2019;25:539-53.

18 Winkler M, Jadassohn. Beitrag zur Frage der "Sarkoide" (Boeck), resp. der subkutanen nodulären Tuberkulide (Darier). Arch. f. Dermat. 1905;77:3-24.

19 Heerford CF. Über eine „Febris uveo-parotidea subchronica“, an der Glandula parotis und der Uvea des Auges lokalisiert und häufig mit Paresen cerebrospinaler Nerven kompliziert. Graefes Arhiv für Ophthalmologie 1909;70:254-73.

20 Colover J. Sarcoidosis with central nervous system involvement. Brain 1948;71:451-75.

21 Wiederholt WC, Siekert RG. Neurological manifestations of sarcoidosis. Neurology 1965;15:1147-54.

22 James DG, Sharma OP. Neurological complications of sarcoidosis. Proc R Soc Med 1967;60:1169-70.
23 Stern BJ, Krumholz A, Johns C, et al. Sarcoidosis and its neurological manifestations. Arch Neurol 1985;42:909-17.

24 Chen RCY, McLeod JG. Neurological complications of sarcoidosis. Clin Exp Neurol 1987;26:99-112.

25 Delaney P. Neurologic manifestations in sarcoidosis: review of the literature, with a report of 23 cases. Ann Int Med 1977;87:336-45.

26 Pentland BJ, Mitchell D, Cull RE, et al. Central nervous system sarcoidosis. Q J Med 1985;56:457-65.

27 Oksanen V. Neurosarcoidosis: clinical presentations and course in 50 patients. Acta Neurol Scand 1986;73:283-90.

28 Chapelon C, Ziza JM, Piette JC, et al. Neurosarcoidosis: signs, course and treatment in 35 confirmed cases. Medicine 1990;69:261-76.

29 Sharma OP. Neurosarcoidosis: a personal perspective based on the study of 37 patients. Chest 1997;112:220-8.

30 Pavese P, Brion JP, Chabre $\mathrm{O}$, et al. Les atteintes neurologiques de la sarcoïdose. Presse Med 1999;28:168-72.

31 Zajicek JPet al. Central nervous system sarcoidosisdiagnosis and management. OJM 1999;92:103-17.

32 Ferriby D, de Seze J, Stojkovic T, et al. Long-Term follow-up of neurosarcoidosis. Neurology 2001;57:927-9.

33 Allen RK, Sellars RE, Sandstrom PA. A prospective study of 32 patients with neurosarcoidosis. Sarc Vasc Diffuse Lung Dis 2003;20:118-25

34 Kellinghaus C, Schilling M, Lüdemann P. Neurosarcoidosis: clinical experience and diagnostic pitfalls. Eur Neurol 2004;51:84-8.

35 Spencer TS, Campellone JV, Maldonado I, et al. Clinical and magnetic resonance imaging manifestations of neurosarcoidosis. Semin Arthritis Rheum 2005;34:649-61.

36 Joseph FG, Scolding NJ. Neurosarcoidosis: a study of 30 new cases. J Neurol Neurosurg Psychiatry 2009;80:297-304.

37 Pawate S, Moses H, Sriram S. Presentations and outcomes of neurosarcoidosis: a study of 54 cases. $Q \mathrm{~J} \mathrm{Med}$ 2009;102:449-60.

38 Kidd DP. Sarcoidosis of the central nervous system: clinical features, imaging and CSF results. J Neurol ;2018:1906.

39 Frohman LP, Guirgis M, Turbin RE, et al. Sarcoidosis of the anterior visual pathway: 24 new cases. J Neuroophthalmol $2003 ; 23: 190-7$.

40 Koczman JJ, Rouleau J, Gaunt M, et al. Neuro-Ophthalmic sarcoidosis: the University of Iowa experience. Semin Ophthalmol 2008;23:157-68.

41 Kidd DP, Burton BJ, Graham EM, et al. Optic neuropathy associated with systemic sarcoidosis. Neurol Neuroimmunol Neuroinflamm 2016;3:e270.

42 Bansal S, Yin K, Vishwanath M, et al. Isolated pupil-involving third nerve palsy as the first presentation of sarcoidosis. Neuro-Ophthalmology 2014;38:278-80.

43 Cama E, Santarelli R, Muzzi E, et al. Sudden hearing loss in sarcoidosis: otoneurological study and neuroradiological correlates. Acta Otorhinolaryngol Ital 2011;31:235-8.

44 Carlson M, White JR, Esahbodi M, et al. Cranial base manifestations of neurosarcoidosis: a review of 305 patients. Otol Neurotol 2015;36:156-66.

45 Said G, Lacroix C, Planté-Bordeneuve V, et al. Nerve granulomas and vasculitis in sarcoid peripheral neuropathy: a clinicopathological study of 11 patients. Brain 2002;125:264-675.

46 Burns TM, Dyck PJB, Aksamit AJ, et al. The natural history and long-term outcome of 57 limb sarcoidosis neuropathy cases. J Neurol Sci 2006;244:77-87. 
47 Said G. Sarcoidosis of the peripheral nervous system. Handb Clin Neurol 2013;115:485-95.

48 Zuniga G, Ropper AH, Frank J. Sarcoid peripheral neuropathy. Neurology 1991;41:1558-61.

49 Sawai S, Misawa S, Kobayashi M, et al. Multifocal conduction blocks in sarcoid peripheral neuropathy. Intern. Med. 2010;49:471-4.

50 Mattiassich G, Schubert H, Hutarew G, et al. A rare manifestation of sarcoidosis with sensomotoric neuropathy of the ulnar nerve as the only symptom. Case Reports 2012: bcr2012007430.

51 Fahoum F, Drory VE, Issakov J, et al. Neurosarcoidosis presenting as Guillain-Barré-like syndrome. A case report and review of the literature. J Clin Neuromuscul Dis 2009;11:35-43.

52 Saifee TA, Reilly MM, Ako E, et al. Sarcoidosis presenting as acute inflammatory demyelinating polyradiculoneuropathy. Muscle Nerve 2011;43:296-8.

53 SJ O. Sarcoid polyneuropathy a histologically proved case. Ann Neurol 1980;7:178-81.

54 Vital A, Lagueny A, Ferrer X, et al. Sarcoid neuropathy: clinicopathological study of 4 new cases and review of the literature. Clin Neuropathol 2008;27:96-105.

55 Singhal NS, Irodenko VS, Margeta M, et al. Sarcoid polyneuropathy masquerading as chronic inflammatory demyelinating polyneuropathy. Muscle Nerve 2015;52:664-8.

56 Hoitsma E, Marziniak M, Faber CC, et al. Small fibre neuropathy in sarcoidosis. Lancet 2086;2002:2085.

57 Tavee JO, Karwa K, Ahmed Z, et al. Sarcoidosis-associated small fibre neuropathy in a large cohort: clinical aspects and response to IVIg and anti-TNF alpha treatment. Respir Med 2017;26:135-13.

58 Hoitsma E, Faber CG, van Santen-Hoeufft M, et al. Improvement of small fiber neuropathy in a sarcoidosis patient after treatment with infliximab. Sarc Vasc Diffuse Lung Dis 2006;23:73-7.

59 van Velzen M, Heij L, Niesters M, et al. Ara 290 for treatment of small fiber neuropathy in sarcoidosis. Expert Opin Investig Drugs 2014;23:541-50.

60 Miura S, Kusumoto M, Noda K, et al. Bell-Shaped sensory impairments of all modalities in a neurosarcoidosis patient. Clin Neurol Neurosurg 2007;109:794-8.

61 Uzawa A, Kojima S, Yonezu T, et al. Truncal polyradiculopathy due to sarcoidosis. J Neurol Sci 2009;281:108-9.

62 Hamodat H, Tran A. Neurosarcoidosis resulting in thoracic radiculopathy: a case report. J Med Case Rep 2019;13:130.

63 Langrand C, Bihan H, Raverot G, et al. HypothalamoPituitary sarcoidosis: a multicenter study of 24 patients. QJM 2012;105:981-95.

64 Anthony J, Esper GJ, Ioachimescu A. Hypothalamic-pituitary sarcoidosis with vision loss and hypopituitarism: case series and literature review. Pituitary 2016;19:19-29.

65 Kidd DP. Sarcoidosis of the central nervous system: safety and efficacy of treatment, and experience of biological therapies. Clin Neurol Neurosurg 2020;194:105811.

66 Herring $\mathrm{AB}$, Urich H. Sarcoidosis of the central nervous system. J Neurol Sci 1969;9:405-22.

67 Camp WA, Friersen J. Sarcoidosis of the central nervous system. Arch Neurol 1962;7:432-41.

68 Meyer JS, Foley JM, Campagna-Pinto D. Granulomatous angiitis of the meninges in sarcoidosis. Arch Neurol Psych 1952:587-600.
69 Brown MM, Thompson AJ, Wedzicha JA, et al. Sarcoidosis presenting with stroke. Stroke 1989;20:400-5.

70 Michotte A, Dequenne P, Jacobovitz D, et al. Focal neurological deficit with sudden onset as the first manifestation of sarcoidosis: a case report with MRI follow-up. Eur Neurol 1991;31:376-9.

71 Kim JS, No YJ. Moyamoya-like vascular abnormality in pulmonary sarcoidosis. Cerebrovasc Dis 2006;22:71-3.

72 Corse AM, Stern BJ. Neurosarcoidosis and stroke. Stroke 1990;21:152-3.

73 Brisman JL, Hinduja A, McKinney JS, et al. Successful emergent angioplasty of neurosarcoid vasculitis presenting with strokes. Surg Neurol 2006;66:402-4.

74 González-Aramburu I, Ruiz-Pérez E, Gómez-Román J, et al. Sarcoidosis presenting as transient ischemic attack status. J Stroke Cerebrovasc Dis 2012;21:515-7.

75 Takenaka K, Ito M, KUMAGAI M, et al. Moyamoya disease associated with pulmonary sarcoidosis - Case Report-. Neurol Med Chir 1998;38:566-8.

76 JK K, Lee SW, Choi CH. Moyamoya-like vasculopathy in neurosarcoidosis. J Korean Neurosurg Soc 2009;45:50-2.

77 Kidd DP, McCabe DJ, Wilhelm T, et al. Carotid arteritis causing amaurosis fugax and ischaemic cerebrovascular events in neurosarcoidosis. Clin Neurol Neurosurg 2018;169:103-6.

78 Bathla G, Watal P, Gupta S, et al. Cerebrovascular manifestations in neurosarcoidosis: how common are they and does perivascular enhancement matter? Clin Radiol 2018;73:907

79 O'Dwyer JP, Al-Moyeed BA, Farrell MA, et al. Neurosarcoidosis-related intracranial haemorrhage: three new cases and a systematic review of the literature. Eur J Neurol 2013;20:71-8.

80 Vukojević Z, Ilić TV, Dominović-Kovačević A, et al. Neurosarcoidosis and multiple intracerebral hematomas: an unusual clinical presentation. J Neurol Sci 2017;379:22-4.

81 Pegat B, Drapier S, Morandi X, et al. Spinal cord hemorrhage in a patient with neurosarcoidosis on long-term corticosteroid therapy: case report. BMC Neurol 2015;15:123.

82 Bathla G, Dandapat S, Soni N, et al. Neuroimaging findings in intracranial sarcoid phlebitis: a case report. J Stroke Cerebrovasc Dis 2019;28:369-70.

83 Zamora C, Hung CC, Tomingas C, et al. Engorgement of deep medullary veins in neurosarcoidosis: a common yet underrecognized cerebrovascular finding on SWI. AJNR 2050;2018:2045.

84 Cohen-Aubart F, Galanaud D, Grabli D, et al. Spinal cord sarcoidosis: clinical and laboratory profile and outcome of 31 patients in a case-control study. Medicine 2010;89:133-40.

85 Sakushima K, Yabe I, Nakano F, et al. Clinical features of spinal cord sarcoidosis: analysis of 17 neurosarcoidosis patients. J Neurol 2011;258:2163-7.

86 Sohn M, Culver DA, Judson MA, et al. Spinal cord neurosarcoidosis. Am J Med Sci 2014;347:195-8.

87 Durel C-A, Marignier R, Maucort-Boulch D, et al. Clinical features and prognostic factors of spinal cord sarcoidosis: a multicenter observational study of 20 biopsy-proven patients. J Neurol 2016;263:981-90.

88 Flanagan EP, Kaufmann TJ, Krecke KN, et al. Discriminating long myelitis of neuromyelitis optica from sarcoidosis. Ann Neurol 2016;79:437-47.

89 Kaiboriboon K, Olsen TJ, Hayat GR. Cauda equina and Conus medullaris syndrome in sarcoidosis. Neurologist 2005;11:179-83. 
90 Wegener S, Linnebank M, Martin R, et al. Clinically isolated neurosarcoidosis: a recommended diagnostic path. Eur Neurol 2015;73:71-7.

91 Nozaki K, Scott TF, Sohn M, et al. Isolated neurosarcoidosis: case series in 2 sarcoidosis centers. The Neurologist 2012;18:373-7.

92 Sammarra I, Barbagallo G, Labate A, et al. Value of multimodal imaging approach to diagnosis of neurosarcoidosis. Brain Sci 2019;9:243.

93 Huang JF, Aksamit AJ, Staff NP. Mri and PET imaging discordance in neurosarcoidosis. Neurology 2012;79:1070.

94 Gascon-Bayarri J, Mana J, Martinez-Yelamos S, et al. Neurosarcoidosis: report of 30 cases and a literature survey. Eur J Int Med 2011;22:e125-32.

95 Leonhard SE, Fritz D, Eftimov F, et al. Neurosarcoidosis in a tertiary referral center: a cross-sectional cohort study. Medicine 2016;95:e3277.

96 Wengert O, Rothenfusser-Korber E, Vollrath B, et al. Neurosarcoidosis: correlation of cerebrospinal fluid findings with diffuse leptomeningeal gadolinium enhancement on MRI and clinical disease activity. J Neurol Sci 2013;335:124-30.

97 Bennett D, Bargagli E, Refini RM, et al. New concepts in the pathogenesis of sarcoidosis. Expert Rev Respir Med 2019;13:981-91.

98 Chopra A, Kalkanis A, Judson MA. Biomarkers in sarcoidosis. Expert Rev Clin Immunol 2016;12:1191-208.

99 Bergantini L, Bianchi F, Cameli P, et al. Prognostic biomarkers of sarcoidosis: a comparative study of serum chitotriosidase, ACE, lysozyme, and KL-6. Dis Markers 2019;2019:1-7.

100 Chazal T, Costopoulos M, Maillart E, et al. The cerebrospinal fluid CD4/CD8 ratio and interleukin- 6 and -10 levels in neurosarcoidosis: a multicenter, pragmatic, comparative study. Eur J Neurol 2019;26:1274-80.

101 Massey J, Walker S, Galloway M, et al. Granulomatous CNS inflammation associated with seminoma. J Neurol 2019;266:1389-93.

102 Judson MA, Costabel U, Drent M, et al. The WASOG sarcoidosis organ assessment instrument: an update of a previous clinical tool. Sarc Vasc Diffuse Lung Dis 2014;31:19-27.

103 Stern BJ, Royal W, Gelfand JM, et al. Definition and consensus diagnostic criteria for neurosarcoidosis from the neurosarcoidosis Consortium consensus group. JAMA Neurol 2018;75:1546-53.

104 Baughman RP, Lower EE. Treatment of sarcoidosis. Clin Rev Allergy Immunol 2015;49:79-92.

105 Bitoun S, Bouvry D, Borie R, et al. Treatment of neurosarcoidosis: a comparative study of methotrexate and mycophenolate mofetil. Neurology 2016;87:1-5.

106 Joubert B, Chapelon-Abric C, Biard L, et al. Association of prognostic factors and immunosuppressive treatment with long-term outcomes in neurosarcoidosis. JAMA Neurol 2017;74:1336-44.

107 Saketkoo LA, Baughman RP. Biologic therapies in the treatment of sarcoidosis. Expert Rev Clin Immunol 2016;12:817-25.

108 Jamilloux Y, Cohen-Aubart F, Chapelon-Abric C, et al. Efficacy and safety of tumor necrosis factor antagonists in refractory sarcoidosis: a multicenter study of 132 patients. Semin Arthritis Rheum 2017;47:288-94.

109 Cohen Aubart F, Bouvry D, Galanaud D, et al. Long-Term outcomes of refractory neurosarcoidosis treated with infliximab. J Neurol 2017;264:891-7.

110 Gelfand JM, Bradshaw MJ, Stern BJ, et al. Infliximab for the treatment of CNS sarcoidosis: a multi-institutional series. Neurology 2017;89:2092-100.

111 Riller Q, Cotteret C, Junot H, et al. Infliximab biosimilar for treating neurosarcoidosis: tolerance and efficacy in a retrospective study including switch from the originator and initiation of treatment. J Neurol 2019;266:1073-8.

112 Panselinas E, Rodgers JK, Judson MA. Clinical outcomes in sarcoidosis after cessation of infliximab treatment. Respirology 2009;14:522-8.

113 Vorselaars ADM, Verwoerd A, van Moorsel CHM, et al. Prediction of relapse after discontinuation of infliximab therapy in severe sarcoidosis. Eur Respir J 2014;43:602-9.

114 Kidd DP, Galloway M, Wilhelm T. Relapse of severe neurosarcoidosis with switch from originator infliximab to biosimilar. Neurology. doi:doi:10.1212/WNL. 0000000000009526. [Epub ahead of print: 11 May 2020].

115 Drent M, Cremers JP, Jansen TL, et al. Practical eminence and experience-based recommendations for use of TNF-alpha inhibitors in sarcoidosis. Sarc Vasc Diffuse Lung Dis 2014;31:91-107.

116 Sharp M, Donnelly SC, Moller DR. Tocilizumab in sarcoidosis patients failing steroid sparing therapies and anti-TNF agents. Respir Med 2019;1:100004.

117 Zella S, Kneiphof J, Haghikia A, et al. Successful therapy with rituximab in three patients with probable neurosarcoidosis. Ther Adv Neurol Disord 2018;11:1756286418805732.

118 Judson MA, Baughman RP, Costabel U, et al. Safety and efficacy of ustekinumab or golimumab in patients with chronic sarcoidosis. Eur Respir J 2014;44:1296-307.

119 ZhouT CN, Pouladi N, et al. Identification of JAK-STAT signalling involvement in sarcoidosis severity via a novel micro-RNA-regulated peripheral blood mononuclear cell gene signature. Sci Rep 2017;26:4237.

120 Damsky W, Thakral D, Emeagwali N, et al. Tofacitinib treatment and molecular analysis of cutaneous sarcoidosis. N Engl J Med 2018;379:2540-6.

121 Linke M, Pham HTT, Katholnig K, et al. Chronic signaling via the metabolic checkpoint kinase mTORC1 induces macrophage granuloma formation and marks sarcoidosis progression. Nat Immunol 2017;18:293-302. 